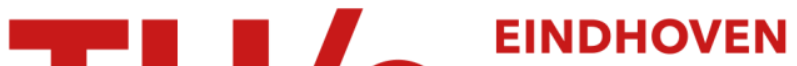 UNIVERSITY OF TECHNOLOGY
}

\section{Implementation of the Neumann Formula for Calculating the Mutual Inductance between Planar PCB Inductors}

\section{Citation for published version (APA):}

Sonntag, C. L. W., Lomonova, E. A., \& Duarte, J. L. (2008). Implementation of the Neumann Formula for Calculating the Mutual Inductance between Planar PCB Inductors. In Proc. The 18th International Conference on Electrical Machines 2008, ICEM 2008, Vilamoura, Portugal 06-09-09-2008 (pp. 1-6). ICEM.

\section{Document status and date:}

Published: 01/01/2008

\section{Document Version:}

Publisher's PDF, also known as Version of Record (includes final page, issue and volume numbers)

\section{Please check the document version of this publication:}

- A submitted manuscript is the version of the article upon submission and before peer-review. There can be important differences between the submitted version and the official published version of record. People interested in the research are advised to contact the author for the final version of the publication, or visit the $\mathrm{DOI}$ to the publisher's website.

- The final author version and the galley proof are versions of the publication after peer review.

- The final published version features the final layout of the paper including the volume, issue and page numbers.

Link to publication

\section{General rights}

Copyright and moral rights for the publications made accessible in the public portal are retained by the authors and/or other copyright owners and it is a condition of accessing publications that users recognise and abide by the legal requirements associated with these rights.

- Users may download and print one copy of any publication from the public portal for the purpose of private study or research.

- You may not further distribute the material or use it for any profit-making activity or commercial gain

- You may freely distribute the URL identifying the publication in the public portal.

If the publication is distributed under the terms of Article 25fa of the Dutch Copyright Act, indicated by the "Taverne" license above, please follow below link for the End User Agreement:

www.tue.nl/taverne

Take down policy

If you believe that this document breaches copyright please contact us at:

openaccess@tue.nl

providing details and we will investigate your claim. 


\title{
Implementation of the Neumann Formula for Calculating the Mutual Inductance between Planar PCB Inductors
}

\author{
C. L. W. Sonntag, E. A. Lomonova, and J. L. Duarte \\ Electromechanics and Power Electronics Group, Department of Electrical Engineering, Eindhoven University of Technology, \\ $5600 \mathrm{MB}$, Eindhoven, The Netherlands \\ E-mail: c.sonntag@tue.nl
}

\begin{abstract}
In this paper, a method for estimating the mutual inductance between two planar printed circuit board inductors with straight tracks is presented. The thin copper tracks are first modeled as multiple straight line filaments. The Neumann formula, derived from the magnetic vector potential and Faraday's law of induction, gives an analytical solution of the mutual inductance. Unfortunately, due to the complexity of this formula, it can only be solved analytically for relatively simple geometries. However, by following the procedure presented in this paper, the mutual inductance between two arbitrary-positioned and orientated planar PCB inductors can be estimated with reduced computational effort by solving the Neumann formula using numerical integration. The proposed method is demonstrated at the hand of two experiments; and the measured and estimated mutual inductances show excellent agreement with a maximum absolute error of less than $5 \%$.
\end{abstract}

\section{INTRODUCTION}

Planar inductors and transformers constructed as copper tracks on printed circuit boards (PCBs) are becoming increasingly popular in the field of contactless energy transfer (CET) and other high frequency electronic systems [2]-[5], [9].

In the case of CET, electronic devices embedded with PCB inductors of various shapes and sizes, transfer power through their shared magnetic field and the inductive coupling between them.

When these inductors (often in the shape of spirals) are excited with relatively low frequency current waveforms, the system is said to operate in a magneto-static mode where the magnetic fields created by these inductors can be approximated by static magnetic fields. With the lack of soft magnetic materials, these fields can be accurately described by the Maxwell equations [1].

The mutual inductance between two inductors is a measure of their magnetic coupling and the amount of shared magnetic field between them. In the CET systems, estimating the mutual inductance between the primary and secondary inductors is vital in determining the capability and efficiency of the power transfer between the devices.

Unfortunately, due to all the different shapes and forms these inductors may take, no straightforward method for calculating their mutual inductances exists.

One existing method for estimating the mutual inductance between such inductors is the finite element method (FEM). This numerical technique approximates the mutual inductance by modeling the inductors in a three-dimensional environment and solving the electromagnetic field equations in and around the devices. Using this purely numerical method, can however be very time consuming especially when complex structures are simulated.

Some papers exist, describing analytical and semi-analytical methods for estimating the mutual inductance between circular conductors. In these papers, the thin conductors are modeled as single current filaments, and thicker conductors as groups of filaments, often called the mesh-matrix method [6], [7], [10], [11].

Unfortunately, in the case of the hexagonal spiral windings (Fig. 1), which are quite attractive in practical applications as used in [2] and [3], the tracks are not circular but consist of multiple straight line segments. A different approach is thus needed for calculating the mutual inductance between theseand other planar PCB inductors with straight tracks.

The problem addressed in this paper is that of developing a method for estimating the mutual inductance between planar PCB inductors with straight tracks.

Firstly, the copper tracks of the planar PCB inductors are modeled as multiple straight line filaments. Secondly, various filament parameters are extracted from the model, e.g. the amount of filaments, the amount of filament vertices as well as their three-dimensional coordinates.

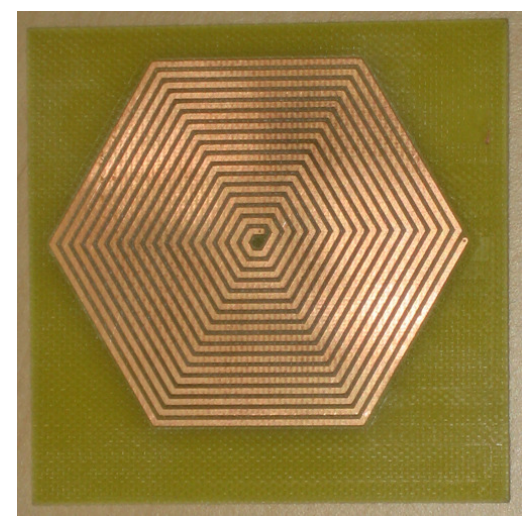

Fig. 1. A planar hexagon spiral winding used in contactless energy transfer applications. 
Proceedings of the 2008 International Conference on Electrical Machines

Finally, the mutual inductance is approximated by implementing a numerical representation of the Neumann formula as an algorithm in a computer program.

The presented method is demonstrated by means of two experiments. In the first experiment, the mutual inductance between two planar hexagon spiral windings used in [2], is estimated. The mutual inductance is first calculated for different relative winding placements, and afterwards measured using the actual PCB windings. In the second experiment, a high frequency planar PCB current transformer is designed. For a certain primary current and required secondary no-load voltage, the desired mutual inductance is first estimated. With the primary winding as a straight track and the secondary winding as a planar rectangular spiral winding, the transformer is realized.

In both experiments the measured and estimated mutual inductances show excellent agreement with a maximum absolute error of less than $5 \%$.

\section{PCB FILAMENT MODEL}

The copper tracks of the PCB inductors are modeled as current filaments, where each straight line segment is modeled by a filament, placed at the center of the track, as show in Fig. 2 .

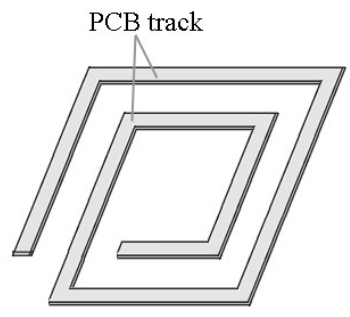

(a)

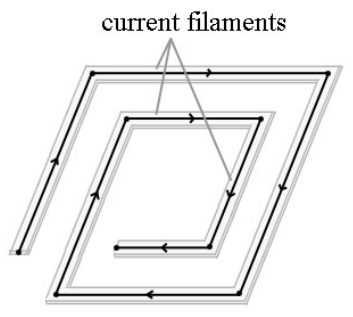

(b)
Fig. 2. (a) A square PCB spiral inductor with two turns, (b) with the copper tracks modeled as current filaments.

\section{ANALYTICAL SOLUTION}

The analytical solution for calculating the mutual inductance between two multi-filament structures is derived using the magnetic vector potential. With the lack of soft magnetic material, and assuming a magneto-static regime, the magnetic vector potential produced by a line current in a filamentary structure is expressed as

$$
\boldsymbol{A}(\boldsymbol{r})=\frac{\mu_{0} I_{1}}{4 \pi} \oint_{l_{1}} \frac{\boldsymbol{d l}}{\left|\boldsymbol{r}-\boldsymbol{r}^{\prime}\right|},
$$

where, as illustrated in Fig. 3, $P$ is the observation point, $\boldsymbol{r}$ is the vector pointing from the axis origin to the observation point, $l$ is the primary filamentary structure contour, $r$ ' is the vector pointing from the axis origin to the structure contour, $\boldsymbol{d} \boldsymbol{l}$ is the infinitesimally small integration element on the contour path, and $I_{1}$ is the total current through the structure.

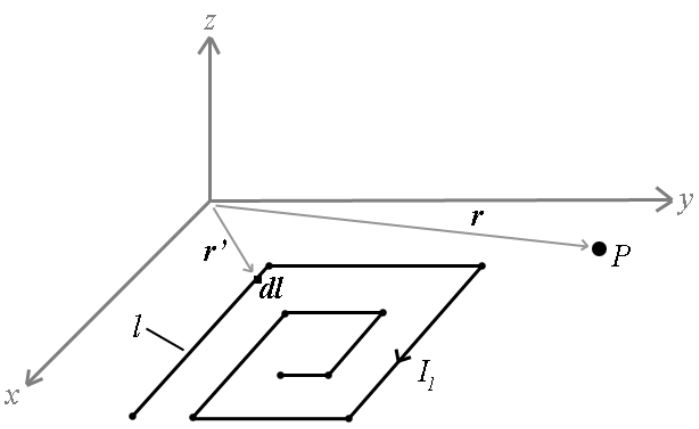

Fig. 3. A multi-filament structure, and the observational point $P$, where the vector potential is evaluated.

The magnetic field relates to the magnetic vector potential though the curl operator, and can be expressed by

$$
\boldsymbol{B}=\nabla \times \boldsymbol{A} .
$$

The magnetic flux linking two filamentary structures can be calculated by integrating the magnetic field produced by the current in the primary structure defined by its contour $l$, through the surface of the secondary structure bounded by its contour $k$. The flux linkage between the two is given as

$$
\lambda(l, k)=\int_{k} \boldsymbol{B}_{l} \cdot d a_{k}
$$

where $\boldsymbol{B}_{\boldsymbol{l}}$ represents the magnetic flux density created by the primary structure on $\boldsymbol{d a} a_{k}$, a surface element on the secondary structure. Using Stokes theorem [1], the surface integral in (3) is converted into a contour integral so that it becomes

$$
\lambda(l, k)=\oint_{k} A_{l} \cdot d k
$$

Combining (1) and (4), the following expression for the flux linkage between the two filamentary structures is formulated as

$$
\lambda(l, k)=\frac{\mu_{0} I_{1}}{4 \pi} \oint_{k} \oint_{/} \frac{d l \cdot d k}{\left|\boldsymbol{r}-\boldsymbol{r}^{\prime}\right|} .
$$

Here, as shown in Fig. 4, $l$ and $k$ are the contours of the primary and secondary filament structures, respectively, $\boldsymbol{d} \boldsymbol{l}$ and $\boldsymbol{d} \boldsymbol{k}$ are infinitesimally small integration elements. 


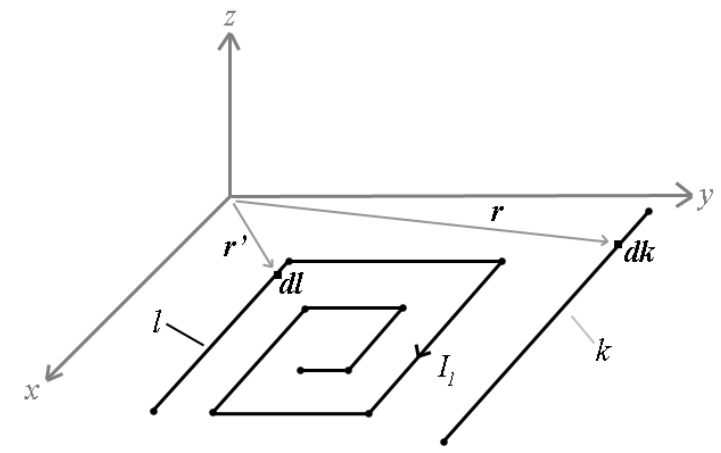

Fig. 4. Primary and secondary filamentary structures, with their respective contours, integration elements, and vectors connecting them to the axis origin.

The mutual inductance between the two filamentary structures is then calculated as:

$$
M(l, k)=\lambda(l, k) / I_{1}
$$

Formula (5) is also known as the Neumann formula [8]. The integral can unfortunately only be completed analytically for relatively few configurations.

\section{NUMERICAL SOLUTION}

Since an analytical solution of (5) is in general quite impractical, numerical integration can be used to approximate it by evaluating the integrant in very small increments. The advantage of using the numerical integration as proposed in this section is that the definite integral in (5) can be implemented with low computational effort to evaluate arbitrary positioned and orientated filamentary structures. The procedure for implementing the numerical integration is shown in the next seven steps:

1. The total amount of straight line segments on the primary filament contour, $l$, and the secondary filament contour, $k$, is determined. They are stored as $a^{l}$ and $a^{k}$, respectively.

2. The total amount of vertices (including the start and stop positions) on the primary and secondary structures are determined. They are stored as $b^{l}$, where $b^{l}=a^{l}+1$, and $b^{k}$, where $b^{k}=a^{k}+1$, respectively.

3. The three-dimensional coordinates of the primary- and secondary vertices are determined and stored in vectors $\boldsymbol{q}^{l}$ and $\boldsymbol{q}^{k}$, respectively.

4. The Euclidean lengths of all the primary and secondary filaments are then calculated and stored in the arrays $c^{l}$, and $c^{k}$, respectively.

5. The normalized filament vectors are calculated as:

$$
\boldsymbol{n}_{m}^{l}=\frac{\boldsymbol{q}_{m+1}^{l}-\boldsymbol{q}_{m}^{l}}{c_{m}^{l}}, m \in\left[1 \ldots a^{l}\right] .
$$

Here, $\boldsymbol{n}^{l}$ represents the normalized position vectors for the primary structure filaments. Similarly, the normalized position vectors for the secondary filaments can be calculated and is represented as $\boldsymbol{n}^{k}$. The subscript $m$ denotes the appropriate filament.

6. The flux linkage between the primary and secondary structures is then estimated as:

$$
\lambda^{\prime}(l, k)=\frac{\mu_{0} I_{1} \Delta_{l} \Delta_{k}}{4 \pi} \sum_{\alpha=1}^{a^{l}} \sum_{\beta=1}^{a^{k}} \sum_{\chi=0}^{\mathrm{X}} \sum_{\varepsilon=0}^{\mathrm{E}} \frac{\boldsymbol{n}_{\alpha}^{l} \cdot \boldsymbol{n}_{\beta}^{k}}{\left|\boldsymbol{K}_{\chi}-\boldsymbol{K}_{\varepsilon}\right|},
$$

where

$$
\begin{aligned}
& \boldsymbol{K}_{\chi}=\boldsymbol{q}_{\alpha}^{l}+(\chi)\left(\Delta_{l}\right) \cdot \boldsymbol{n}_{\alpha}^{l}, \\
& \boldsymbol{K}_{\varepsilon}=\boldsymbol{q}_{\beta}^{k}+(\varepsilon)\left(\Delta_{k}\right) \cdot \boldsymbol{n}_{\beta}^{k}, \\
& \mathrm{X}=c_{\alpha}^{l} / \Delta_{l}, \mathrm{E}=c_{\beta}^{k} / \Delta_{k} .
\end{aligned}
$$

Here, the lengths $\Delta_{l}$ and $\Delta_{k}$ are small numerical integration elements.

7. Finally, the mutual inductance between the two filaments can then be estimated from (6) as:

$$
M^{\prime}(l, k)=\lambda^{\prime}(l, k) / I_{1}
$$

Caution must be taken when choosing the values for $\Delta_{l}$ and $\Delta_{k}$. On the one hand, choosing these values too small will increase the accuracy of the model but also increase the processing time needed to solve the numerical integral. On the other hand, choosing these values to big reduces the model accuracy. By iterating (8) with decreasing values of $\Delta_{l}$ and $\Delta_{k}$ the convergence of the resultant mutual inductance can be used as a gauge in determining the accuracy of the model. Generally, these values should be about the same order of magnitude (preferably smaller) than the PCB track thickness and track spacing.

\section{EXPERIMENTAL VALIDATION}

The method for estimating the mutual inductance proposed in this paper is demonstrated at the hand of two experiments. In these experiments no soft magnetic material is present, a magneto-static regime is assumed, and all current and voltage calculations and measurements are sinusoidal steady state waveforms. In both cases the mutual inductances are measured by exciting the primary winding with a current waveform and measuring the no-load secondary induced voltage. Assuming no (or negligible) secondary current, the mutual inductance is 
Proceedings of the 2008 International Conference on Electrical Machines

estimated using:

$$
\left|V_{2}\right|=j \omega\left|I_{1}\right| M_{12}
$$

Here $I_{l}$ is the current amplitude and $\omega$ is the radial frequency of the primary current; $V_{2}$ is the secondary induced voltage and $M_{12}$ is the mutual inductance between the primary and secondary winding.

\section{A. Hexagon spiral winding mutual inductance}

In [2], a contactless energy transfer (CET) platform is presented. In this system, power is transferred from a primary CET platform embedded with a matrix hexagon spiral windings to secondary devices (e.g. mobile phones, PDAs and laptops) embedded with similar receiving windings, through inductive coupling.

Accurate estimation of the mutual inductance between the primary and secondary windings are vital in developing the power electronics circuits required to power the system, and determining the systems' capabilities as a whole. The physical dimensions of the primary and secondary hexagon spiral windings are specified in Table I.

TABLE I

PHYSICAL DIMENSIONS OF THE HEXAGON SPIRAL WINDINGS

\begin{tabular}{c|c|c}
\hline \hline Parameter & $\begin{array}{c}\text { Primary Winding } \\
\text { Value }\end{array}$ & $\begin{array}{c}\text { Secondary } \\
\text { Winding Value }\end{array}$ \\
\hline Radius & $12 \mathrm{~mm}$ & $20 \mathrm{~mm}$ \\
Turns & 13 & 23 \\
Thickness & $105 \mu \mathrm{m}$ & $105 \mu \mathrm{m}$ \\
Track width & $0.5 \mathrm{~mm}$ & $0.5 \mathrm{~mm}$ \\
Track spacing & $0.25 \mathrm{~mm}$ & $0.25 \mathrm{~mm}$ \\
\hline \hline
\end{tabular}

Using the techniques described in this paper, the mutual inductance between a single primary winding and a single secondary winding is first calculated and then measured. With, $\Delta_{l}=\Delta_{k}=0.5 \mathrm{~mm}$, the primary winding is kept at the axis origin, the secondary winding is shifted parallel to the primary at different $x-, y$-, and $z$-coordinates, as shown in Fig. 5.

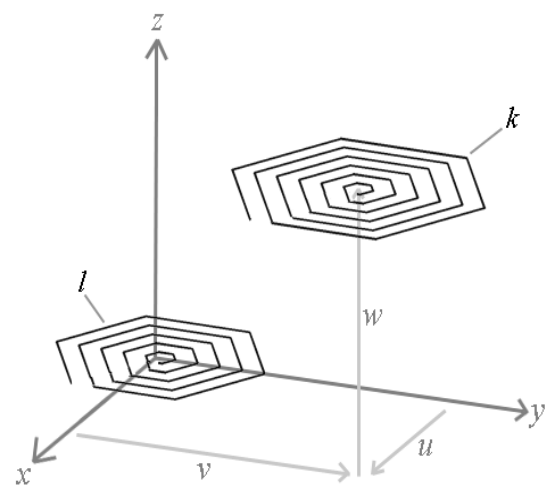

Fig. 5. The position of the primary- and secondary hexagon spiral windings during mutual inductance calculation and measurements.

Fig. 6, shows part of the setup used to measure the mutual inductance. Here the secondary hexagon spiral winding is placed on top of a matrix of hexagon spiral windings. The activated primary winding is hidden underneath the secondary winding. White plastic spacers are used to separate the windings. The current probe, measuring the primary current, and voltage probe, measuring the secondary induced voltage, can also be seen.

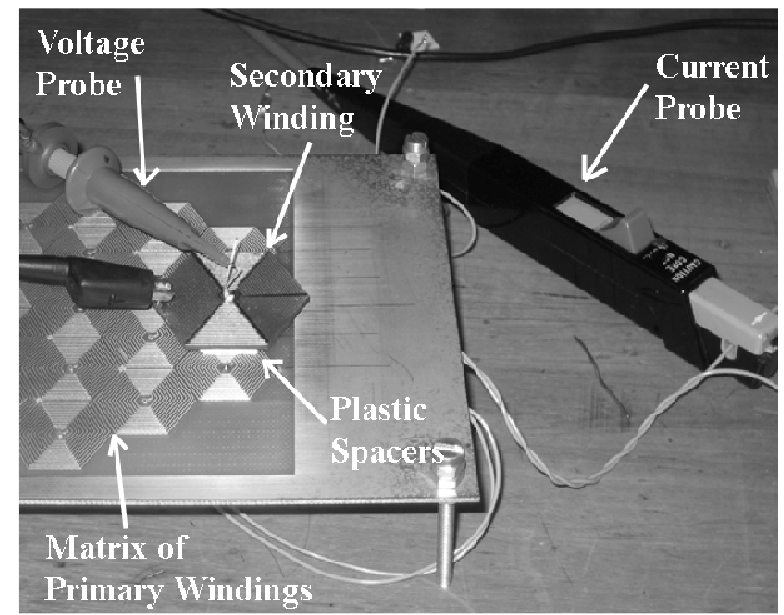

Fig. 6. The setup used to measure the mutual inductance between the hexagon spiral windings.

The results of the calculated and measured mutual inductances are shown in Table II.

TABLE II

Results of The Mutual InduCTANCE CALCUlations AND MEASUREMENTS.

\begin{tabular}{c|c|c|c}
\hline \hline $\begin{array}{c}\text { Secondary } \\
\text { winding position } \\
(u, v, w)[\mathrm{mm}]\end{array}$ & $\begin{array}{c}\text { Calculated } \\
\text { Mutual } \\
\text { Inductance }\end{array}$ & $\begin{array}{c}\text { Measured } \\
\text { Mutual } \\
\text { Inductance }\end{array}$ & Error \\
\hline $0,0,2$ & $3.20 \mu \mathrm{H}$ & $3.16 \mu \mathrm{H}$ & $-1.27 \%$ \\
$0,0,3$ & $2.75 \mu \mathrm{H}$ & $2.64 \mu \mathrm{H}$ & $-4.17 \%$ \\
$0,0,4$ & $2.37 \mu \mathrm{H}$ & $2.35 \mu \mathrm{H}$ & $-0.85 \%$ \\
$0,0,5$ & $2.05 \mu \mathrm{H}$ & $2.01 \mu \mathrm{H}$ & $-1.99 \%$ \\
$10.4,0,2$ & $1.40 \mu \mathrm{H}$ & $1.43 \mu \mathrm{H}$ & $2.10 \%$ \\
$10.4,0,3$ & $1.25 \mu \mathrm{H}$ & $1.29 \mu \mathrm{H}$ & $3.10 \%$ \\
$10.4,0,4$ & $1.11 \mu \mathrm{H}$ & $1.15 \mu \mathrm{H}$ & $3.48 \%$ \\
$10.4,0,5$ & $1.00 \mu \mathrm{H}$ & $1.03 \mu \mathrm{H}$ & $2.91 \%$ \\
$12,0,2$ & $900 \mathrm{nH}$ & $916 \mathrm{nH}$ & $1.75 \%$ \\
$12,0,3$ & $826 \mathrm{nH}$ & $802 \mathrm{nH}$ & $-3.00 \%$ \\
$12,0,4$ & $760 \mathrm{nH}$ & $751 \mathrm{nH}$ & $-1.20 \%$ \\
$12,0,5$ & $700 \mathrm{nH}$ & $716 \mathrm{nH}$ & $2.23 \%$ \\
\hline \hline
\end{tabular}

\section{B. High frequency planar current transformer}

In order to control the power transfer in the CET system presented in [2], the controller needs to measure the current through each activated primary hexagon spiral winding. To do this, a high frequency current transformer is implemented as copper traces on a PCB. The primary winding is a straight 
track (to minimize the introduced inductance) placed in the current path, and the induced voltage over the secondary winding is sampled and measured by the controller using a high speed analog-to-digital converter (ADC). The ADC has an extremely large input resistance $(5-20 \mathrm{k} \Omega)$ and the secondary current is assumed to be zero.

For a current frequency of $2.7 \mathrm{MHz}$, a secondary induced voltage of $1 \mathrm{~V}$ (rms) per $1 \mathrm{~A}$ (rms) of primary current is required. The necessary mutual inductance is estimated as $57.31 \mathrm{nH}$. The general shape of the transformer is shown in Fig. 7, and the physical dimensions are determined through a parametric search through the variables shown in the figure. Values of $\Delta_{l}$ and $\Delta_{k}$ equal to $1 \mathrm{~mm}$ are used.

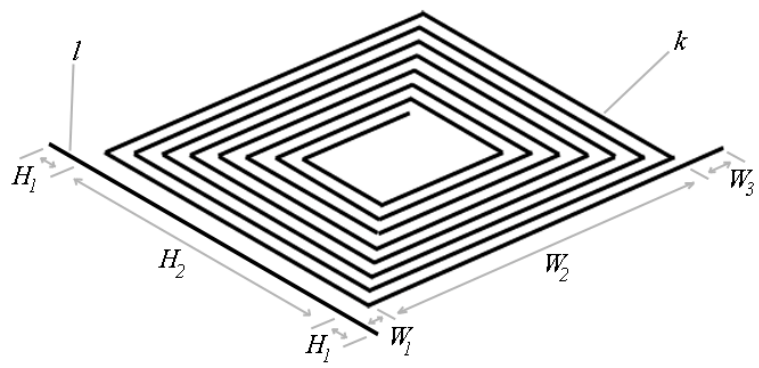

Fig. 7. The planar PCB transformer model.

The physical dimensions of the developed PCB transformer are presented in Table III.

TABLE III

PhysicAl Dimensions OF THE PCB CURRENT TRANSFORMER

\begin{tabular}{c|c}
\hline \hline Parameter & Value \\
\hline$H_{l}$ & $5 \mathrm{~mm}$ \\
$H_{2}$ & $40 \mathrm{~mm}$ \\
$W_{l}$ & $3 \mathrm{~mm}$ \\
$W_{2}$ & $42 \mathrm{~mm}$ \\
$W_{3}$ & $5 \mathrm{~mm}$ \\
\hline \hline
\end{tabular}

The implemented PCB transformer has a track thickness of 1 $\mathrm{mm}$ and copper thickness of $35 \mu \mathrm{m}$, and is shown in Fig. 8.

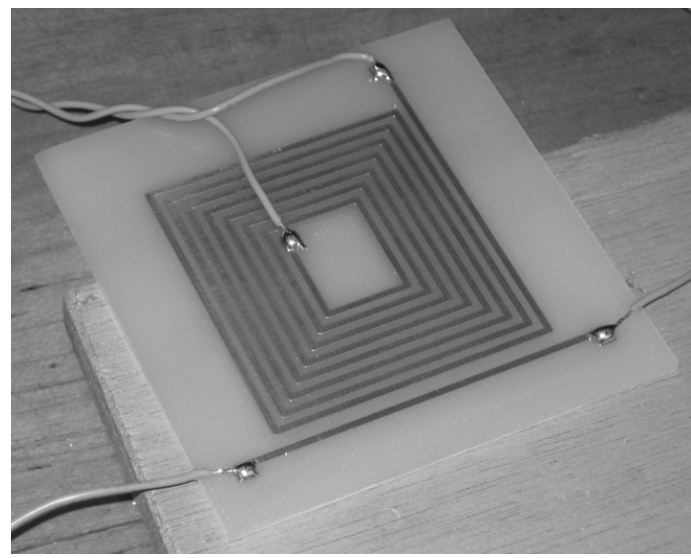

Fig. 8. The actual planar PCB current transformer.
The mutual inductance is measured as $56.10 \mathrm{nH}$, which gives an error of approximately $-2.5 \%$.

\section{CONCLUSIONS}

In this paper, a method for estimating the mutual inductance between PCB inductors with straight tracks is presented.

The copper tracks of the PCB inductors are first modeled as multiple straight line filaments of which various parameters are then extracted (e.g. the amount of filaments, the amount of filament vertices as well as their three-dimensional coordinates). The mutual inductance is then approximated by implementing a numerical representation of the Neumann formula as an algorithm in a computer program.

The presented method is demonstrated by means of two experiments. In the first experiment, the mutual inductance between two planar hexagon spiral winding used in a CET system [2], is estimated. The mutual inductance is first calculated and afterwards measured using the actual PCB windings, for different relative winding placements. In the second experiment, a high frequency planar PCB current transformer is designed. For a certain primary current and required secondary no-load voltage, the desired mutual inductance is first estimated. With the primary winding as a straight track and the secondary winding as a planar rectangular spiral winding, the transformer is realized.

In both experiments the measured and estimated mutual inductances show excellent agreement with a maximum absolute error of less than $5 \%$.

\section{ACKNOWLEDGEMENTS}

The authors would like to thank F. B. M. v. Horck, M. A. M. Hendrix, A. J. M. Pemen and M. J. P. C. Uyt de Willigen for their valuable discussions and help regarding this work.

\section{REFERENCES}

[1] Herman A. Hous, and James R. Melcher, "Electromagnetic Fields and Energy," Massachusetts Institute of Technology, pp. 310-322, 1998.

[2] C. L. W. Sonntag, E. A. Lomonova, J. L. Duarte and A. J. A. Vandenput, "Specialized Receiver for Three-Phase Contactless Energy Transfer Desktop Applications," The 12th European Conference on Power Electronics and Applications, EPE 2007, Aalborg, pp. 1-11, September 2007.

[3] S. Y. R. Hui and W. C. Ho, "A New Generation of Universal Contactless Battery Charging Platform for Portable Consumer Electronic Equipment," The $35^{\text {th }}$ Annual IEEE Power Electronics Specialists Conference, PESC 2004, Germany, pp. 638-644, June 2004.

[4] Byungcho Choi, Jaehyun Nho, Honnyong Cha, Taeyoung Ahn, and Seungwon Choi, "Design and Implementation of Low-Profile Contactless Battery Charger Using Planar Printed Circuit Board Windings as Energy Transfer Device," IEEE Transactions on Industrial Electronics, Vol. 51, No. 1, pp. 140-147, February 2004.

[5] S.C. Tang, S. Y. Hui, and Henry Shu-Hung Chung, "Coreless Planar Printed-Circuit-Board (PCB) Transformers - A Fundamental Concept for Signal and Energy Transfer," IEEE Transactions on Power Electronics, Vol. 15, No. 5, pp. 931-941, September 2000.

[6] Ki-Bing Kim, Enrico Levi, Zivan Zabar, and Leo Birenbaum, "Mutual Inductance of Noncoaxial circular Coils with Constant Current Density," 
Proceedings of the 2008 International Conference on Electrical Machines

IEEE Transactions on Magnetics, Vol. 33, No. 5, pp. 4303-4308, September 1997.

[7] C. Fernandez, R. Prieto, O. Garcia, and J. A. Cobos, "Coreless Magnetic Transformer Design Procedure," The $36^{\text {th }}$ IEEE Power Electronics Specialists Conference, PESC 2005, Brazil, pp. 1548-1554, June 2005.

[8] H. L. Chan, K. W. E. Cheng, and D. Sutanto, "A simplified Neumann's Formula for Calculation of Inductance of Spiral Coil," The $8^{\text {th }}$ International Conference on Power Electronics and Variable Speed Drives, London, pp. 69-73, September 2000.
[9] J. Achterberg, E. Lomonova, J. de Boeij, "Coil Array Structures Compared for Contactless Battery Charging Platform," IEEE Transactions on Magnetics, Vol. 44, No. 5, pp. 617-622, May 2008.

[10] Y. P. Su, Xun Liu, S. Y. R. Hui, "Mutual Inductance Calculation of Movable Planar Coils on Parallel Surfaces," The $39^{\text {th }}$ IEEE Annual Power Electronics Specialists Conference, PESC 2008, Greece, pp. 34763481, June 2008.

[11] Slobodan I. Babic, and Cevdet Akyel, "New Analytical-Numerical Solutions for the Mutual Inductance of Two Coaxial Circular Coils with Rectangular Cross Section in Air," IEEE Transactions on Magnetics, Vol. 42, No. 6, pp. 1661-1669, June 2006. 